\title{
IMPACT OF A ONCE-THROUGH COOLING SYSTEM ON THE YELLOW PERCH STOCK IN THE WESTERN BASIN OF LAKE ERIE*
}

\author{
A.L. JENSEN \\ School of Natural Resources, University of Michigan, Ann Arbor, MI 48109 (U.S.A.)
}

(Accepted for publication 31 July 1981)

\begin{abstract}
Jensen, A.L., 1982. Impact of a once-through cooling system on the yellow perch stock in the western basin of Lake Erie. Ecol. Modelling, 15: 127-144.

The surplus production model, a conventional fishery stock assessment model, is applied to assess the entrainment and impingement impact of the Monroe Power Plant on the yellow perch standing stock and fishery in the western basin of Lake Erie. Biological parameters of the model are estimated from commercial catch and effort data and entrainment and impingement coefficients are estimated from power plant data. The model is applied to estimate stock biomass, egg production, and larva production: the proportions entrained and impinged are then estimated. The impact of water withdrawal on the equilibrium standing stock and maximum sustainable yield from the fishery is estimated and the impact of increased water withdrawal is simulated. The impact on equilibrium standing stock and the maximum sustainable yield are larger than the proportion of the standing stock entrained and impinged, but the impact of the Monroe Power Plant is relatively small; it decreases biomass and the maximum sustainable yield of the yellow perch stock by only a few percent. However, there are several power plants impacting the yellow perch stock of the western basin of Lake Erie and the combined impact should be examined.
\end{abstract}

\section{INTRODUCTION}

The surplus production model, a conventional fishery stock assessment model, is applied for assessment of the impact of the Monroe Power Plant on the yellow perch stock in the western basin of Lake Erie. The Monroe Power Plant is a 4 unit 3150 megawatt coal-fired plant located on the western shore of Lake Erie south of the Raisin River (Fig. 1). The plant uses once-through cooling and has a pumping capacity of $0.29 \times 10^{10} \mathrm{~m}^{3} / \mathrm{y}$. A

\footnotetext{
* This study was supported by the U.S. Environmental Protection Agency.
} 


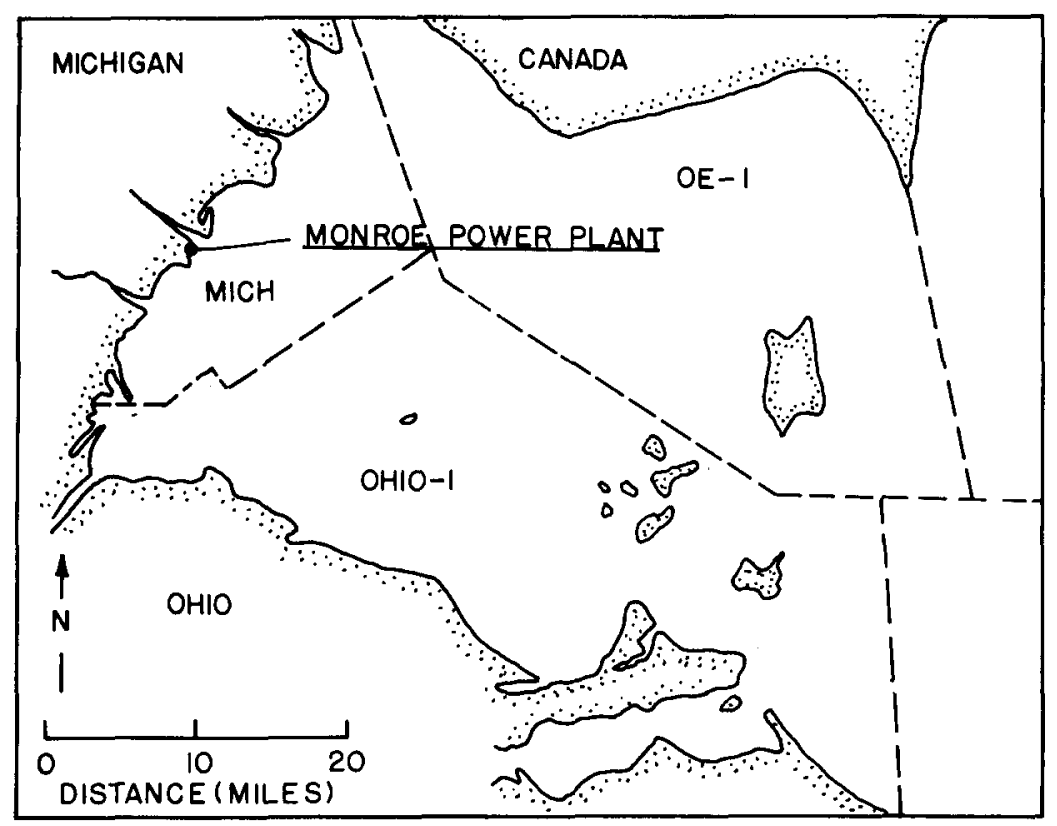

Fig. 1. Western Lake Erie showing location of the Monroe Power Plant and the fishery statistical districts Mich, OE-1, and Ohio-1.

full discussion of plant operation and entrainment and impingement at the plant are provided by Anon. (1976), Cole (1978), and Patterson (1979).

The yellow perch ( Perca flavesencs), a highly-valued sport and commercial species, is one of the most frequently impinged and entrained fish at the power plant. Considerable information on yellow perch is available, and much of the biological information for the species has been summarized in the synopsis by Thorpe (1977).

Commercial catch and effort data are applied to estimate model parameters and the fitted model is applied to estimate stock size and the number of eggs and larvae produced. The model also is applied to determine the proportion of the standing stock impinged and the proportion of larvae entrained, and to determine the impact of entrainment and impingement on the standing stock and the maximum sustainable yield. The impact on the biomass of the stock and maximum sustainable yield of increased water withdrawals is simulated.

\section{MODEL DEVELOPMENT}

In stock assessment the conventional approach is to divide the stock into a recruited portion which is vulnerable to fishing and a non-recruited portion 
which is younger life stages that are not vulnerable to fishing. Stock assessment models are constructed for the recruited stock. Biomass is added to the exploited stock by growth and recruitment and biomass is lost through natural mortality and fishing mortality. Surplus production is the amount of biomass that can be removed from a population without causing a change in the size of the population. Biomass removed is replaced by growth and recruitment. Surplus production is small at both high and low population sizes and attains a maximum at some intermediate population size.

The mathematical form of the logistic surplus production model is (Jensen, 1978)

$$
\begin{aligned}
& \frac{\mathrm{d} Y}{\mathrm{~d} t}=q E B \\
& \frac{\mathrm{d} B}{\mathrm{~d} t}=k B-\left(k / B_{\infty}\right) B^{2}-q E B
\end{aligned}
$$

where: $Y=$ cumulative yield from the fishery

$q=$ catchability coefficient

$E \quad=$ fishing effort

$B=$ biomass of the exploited stock

$k=$ population growth coefficient

$B_{\infty}=$ environmental carrying capacity

Usually, impingement will operate on younger fish as well as on those recruited into the exploited stock. Yellow perch, for example, are recruited at age 3 , but become vulnerable to impingement as yearlings. Biomass of the exploited stock and biomass of the unexploited stock vulnerable to impingement, $B_{\text {un }}$, are related as $B(t)=f\left(B_{\text {un }}(t-T)\right)$ where $T$ is the difference between the mean age of adults and the mean age of impingeable but unexploited individuals. For simplicity and to avoid time lags it is assumed that the biomass of the impingeable but unexploited portion of the stock is proportional to the exploited portion of the stock, i.e., $B_{\text {un }}=c B$. This assumption is adequate because, as will be shown later, large changes in biomass have little effect on the rate of impingement. The equation for impingement can be written as

$$
\frac{\mathrm{d} I}{\mathrm{~d} t}=f^{\prime} Q B_{\mathrm{I}}=f^{\prime} Q(1+c) B=f Q B
$$

$$
\text { where: } \begin{aligned}
f & =\text { impingement coefficient } \\
f^{\prime} & =\text { impingement coefficient } \\
Q & =\text { volume flow into the plant } \\
B & =\text { biomass of the exploited population } \\
B_{\mathrm{I}} & =\text { impingeable biomass }\left(B+B_{\text {un }}\right) \\
B_{\mathrm{un}} & =\text { impingeable biomass not recruited into the exploited stock } \\
c & =\text { proportionality constant }
\end{aligned}
$$


Application of the surplus production model for assessment of entrainment requires further modification of the model. The loss of larvae and eggs by entrainment must be expressed in terms of an equivalent loss of biomass from the exploited stock. The rate of egg entrainment is

$$
\frac{\mathrm{d} G}{\mathrm{~d} t}=p Q \bar{G}
$$

where $G$ is the number of eggs entrained at time $t, p$ is the egg entrainment coefficient, and $\bar{G}$ is the average number of eggs present in the lake during the spawning season. The average number of eggs is

$\bar{G}_{0}=G\left(2-\phi_{1}\right) / 2$

where $\phi_{1}$ is the mortality rate during the egg stage and $G_{0}$ is the number of eggs produced which is

$G_{0}=B \cdot E U B$

where $E U B$ is the number of eggs produced per unit of adult biomass. Substitution of eq. 5 into eq. 4 , differentiation, and solution for $\mathrm{d} B / \mathrm{d} t$ gives

$\frac{\mathrm{d} B}{\mathrm{~d} t}=\frac{2}{E U B\left(2-\phi_{1}\right)} \frac{\mathrm{d} \bar{G}}{\mathrm{~d} t}$

as the relation between change in biomass and change in the average number of eggs. This same equation applies to the relation between change in biomass as a result of entrainment, $(\mathrm{d} B / \mathrm{d} t)_{\mathrm{e}}$, and entrainment loss of eggs from the population, $(\mathrm{d} \bar{G} / \mathrm{d} t)_{\mathrm{e}}$

$$
\left(\frac{\mathrm{d} B}{\mathrm{~d} t}\right)_{\mathrm{e}}=\frac{2}{E U B\left(2-\phi_{1}\right)}\left(\frac{\mathrm{d} G}{\mathrm{~d} t}\right)_{\mathrm{e}}
$$

Loss of eggs from the population by entrainment equals accumulation of entrained eggs at the power plant but the rates are of opposite sign, hence

$$
\left(\frac{\mathrm{d} B}{\mathrm{~d} t}\right)_{\mathrm{e}}=-\frac{2}{E U B\left(2-\phi_{1}\right)} \frac{\mathrm{d} G}{\mathrm{~d} t}
$$

and substitution from eqs. 3 and 4 and cancellation of terms gives

$$
\left(\frac{\mathrm{d} B}{\mathrm{~d} t}\right)_{\mathrm{e}}=-p Q B
$$

A similar approach is applied to obtain the relation between larval entrainment and the rate of biomass decrease. The initial number of larvae produced by the $G_{0}$ eggs is

$L_{0}=\left(1-\phi_{1}\right) G_{0}$

The average number of larvae is

$\bar{L}=L_{0}\left(2-\phi_{2}\right) / 2$ 
where $\phi_{2}$ is the mortality rate during the larval stage. The rate of entrainment of larvae is

$$
\frac{\mathrm{d} L}{\mathrm{~d} t}=h Q L
$$

and the rate of change in biomass resulting from larval entrainment is

$$
\left(\frac{\mathrm{d} B}{\mathrm{~d} t}\right)_{\mathrm{a}}=-h Q B
$$

where $h$ is an entrainment coefficient for larvae. To apply this model it is not necessary to specify duration of the different life stages and it is not necessary to estimate $\phi_{2}$.

Combining the above results gives the surplus production model

$$
\begin{aligned}
& \frac{\mathrm{d} Y}{\mathrm{~d} t}=q E B \\
& \frac{\mathrm{d} I}{\mathrm{~d} t}=f Q B \\
& \frac{\mathrm{d} L}{\mathrm{~d} t}=h Q B \\
& \frac{\mathrm{d} G}{\mathrm{~d} t}=p Q B \\
& \frac{\mathrm{d} B}{\mathrm{~d} t}=k B-\left(k / B_{\infty}\right) B^{2}-q E B-f Q B-p Q B-h Q B
\end{aligned}
$$

Equations 14 are applied to estimate biomass of the stock and the number of eggs and larvae produced. They also are applied to examine the separate and combined impacts of impingement and entrainment on standing stock. yield, and maximum sustainable yield.

\section{ESTIMATION OF BIOLOGICAL PARAMETERS}

The biological and fisheries related parameters of the model $-k, B_{\infty}$, and $q$-were estimated using commercial catch and effort data for the 3 fishery statistical districts in western Lake Erie: Ohio-1, Mich, and OE-1 in Ontario (Fig. 1). Data for 1964-1977 were available from the United States Fish and Wildlife Service and the Ontario Ministry of Natural Resources. The major fishing gears used in these districts were 2 in. gill nets, shallow trap nets, and pound nets. Data for all districts were summed; pound nets were selected as the standard gear and the pound net effort necessary to make the entire catch was calculated as

pound net effort $=$ total catch $/$ pound net catch per unit effort

To estimate the biological parameters a non-linear least squares method 
was applied to minimize the residual sum of squares

$\sum\left(Y(t)_{\mathrm{a}}-\hat{Y}(t)_{\mathrm{a}}\right)^{2}$

where $Y(t)_{\mathrm{a}}$ is the observed annual yield for year $t$ and $\hat{Y}(t)_{\mathrm{a}}$ is the estimated annual yield for year $t$. Estimated yield was obtained from the solution of the yield equation. Separation of variables and integration gives annual yield as

$\hat{Y}(t)_{\mathrm{a}}=Y(t+1)-Y(t)=q E(t) \int_{t}^{t+1} B(t) \mathrm{d} t$

and application of the trapezoidal rule gives

$\hat{Y}(t)_{\mathrm{a}}=q E(t)[(B(t+1)+B(t)) / 2]$

Biomass at time $t$ was calculated from the solution to the biomass equation which is

$B(t)=\left\{\frac{k}{B_{\infty}(k-q E)}+\left[\frac{1}{B_{0}}-\frac{k}{B_{\infty}(k-q E)}\right] \mathrm{e}^{-(k-q E) t}\right\}^{-1}$

where $B_{0}$ is the initial biomass and is calculated as $1 / q$ times the catch per unit of effort of the initial year.

The fit of the model is poor from 1964-1972 but the fit is good from 1972-1977 (Fig. 2). Large changes occurred in the yellow perch population between 1964 and 1977 and these changes are reflected in the catch statistics.

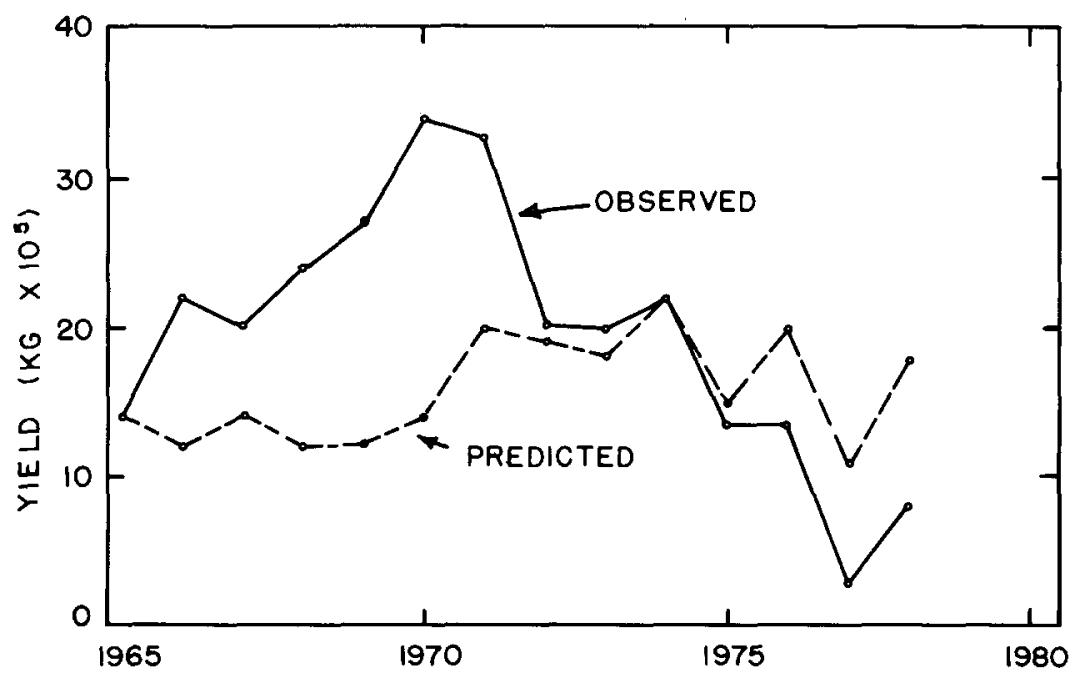

Fig. 2. Observed yellow perch yield from western Lake Erie and yield calculated using the fitted surplus production model (dashed line). 
Changes also occurred in the fishery regulations. The impingement and entrainment data were obtained during 1974 and 1975 and during this period the model describes the dynamics of the fishery well.

For assessment of entrainment, the mortality parameter $\phi_{1}$ for the egg stage must be determined. Values in the literature indicate that $\phi_{1}$ is between 0.50 and 0.70 (Patterson, 1979). In this study $\phi_{1}$ was set at 0.99 . This high egg mortality results in a higher larval entrainment impact, but even with this high mortality the impact of entrainment is considerably smaller than the impact of impingement. The effect on the results of different values of $\phi$ is examined.

\section{ESTIMATION OF ENTRAINMENT AND IMPINGEMENT COEFFICIENTS}

From estimates of annual biomass impinged, numbers entrained, and the observed volume flow, the entrainment and impingement coefficients were calculated. Integration of the impingement equation gives

$\Delta I=I(t+1)-I(t)=f Q \int_{t}^{t+1} B(t) \mathrm{d} t=f Q \bar{B}$

and the impingement coefficient was estimated as

$\hat{f}=\Delta I / Q \bar{B}$

where $\bar{B}$ is the average biomass during the year.

Egg entrainment data are not available for the Monroe Power Plant so only larval entrainment can be assessed. The larval entrainment coefficient was estimated using the equation

$\hat{h}=\Delta L / Q \bar{B}$

The average biomass of the stock necessary for estimation of $f$ and $h$ was calculated using the surplus production model. The biomass estimates are

\section{TABLE I}

Summary of power plant intake data, commercial catch, and stock size estimates

\begin{tabular}{lllll}
\hline Parameter & 1972 & 1973 & 1974 & 1975 \\
\hline Yield (kg) & $2.0 \times 10^{6}$ & $2.0 \times 10^{6}$ & $2.2 \times 10^{6}$ & $1.4 \times 10^{6}$ \\
Population biomass & $8.7 \times 10^{6}$ & $7.4 \times 10^{6}$ & $6.5 \times 10^{6}$ & $5.2 \times 10^{6}$ \\
Number impinged & $1.7 \times 10^{5}$ & $2.2 \times 10^{5}$ & $1.5 \times 10^{5}$ & $1.7 \times 10^{5}$ \\
Biomass impinged & $4.3 \times 10^{4}$ & $5.7 \times 10^{4}$ & $4.0 \times 10^{4}$ & $4.6 \times 10^{4}$ \\
Number larvae entrained & - & $2.2 \times 10^{6}$ & $8.3 \times 10^{7}$ & $2.9 \times 10^{7}$ \\
Volume flow $\left(\mathrm{m}^{3} / \mathrm{y}\right)$ & - & - & $0.17 \times 10^{10}$ & -
\end{tabular}


TABLE II

Summary of parameter estimates

\begin{tabular}{lll}
\hline Parameter & Symbol & Estimate \\
\hline Growth parameter & $k$ & 0.70 \\
Catchability coefficient & $q$ & 0.00001 \\
Carrying capacity $(\mathrm{kg})$ & $B_{\infty}$ & $12.0 \times 10^{\circ}$ \\
Impingement coefficient & $f$ & $0.4891 \times 10^{-11}$ \\
Larvae entrainment coefficient & $h$ & $0.2736 \times 10^{-12}$ \\
\hline
\end{tabular}

listed in Table $\mathrm{I}$. The numbers impinged, biomass impinged, and the number of larvae entrained are also listed in Table I. The biomass impinged was calculated using an estimated average individual weight of $0.265 \mathrm{~kg}$. Estimates of the model parameters are listed in Table II.

\section{IMPACT OF ENTRAINMENT AND IMPINGEMENT}

The proportion of the larvae entrained and the proportion of the standing stock impinged are both small (Table III). The impact of this entrainment and impingement on the standing stock and maximum sustainable yield is somewhat larger.

The impact of a power plant is similar to that of a fishery. For a fishery the maximum surstainable yield occurs at a biomass of $B_{x} / 2$ and it is calculated as MSY $=k B_{\infty} / 4$. For the western basin of lake Erie the MSY of yellow perch is $2100000 \mathrm{~kg}$; when this yield is removed annually from the stock, the stock is reduced from the carrying capacity of $12000000 \mathrm{~kg}$ to $6000000 \mathrm{~kg}$. At equilibrium, 35\% of the stock is removed annually, but this removal causes the standing stock to decrease $50 \%$ below the carrying

\section{TABLE III}

Summary of power plant impacts

\begin{tabular}{lll}
\hline Impact & Flow $\left(\mathrm{m}^{3} / \mathrm{y}\right)$ & \\
\cline { 2 - 3 } & $0.186 \times 10^{10}$ & $0.29 \times 10^{10}$ \\
\hline Proportion of standing stock impinged & $1 \%$ & - \\
Proportion of larvae entrained & $5 \%$ & - \\
Reduction in biomass & $1.98 \%$ & $3.08 \%$ \\
Reduction in MSY & $2.72 \%$ & $4.22 \%$ \\
\hline
\end{tabular}


capacity. The decrease in the size of the standing stock is larger than the proportion of the standing stock that is caught. This same result applies to power plant entrainment and impingement. The reduction in the stock is larger than the proportion of the existing stock that is entrained or impinged.

The fitted surplus production model was applied to estimate the reduction in biomass of the standing stock and the reduction in the maximum sustainable yield caused by the Monroe Power Plant. Also, the impact of increased water withdrawal is simulated using the impingement and entrainment coefficients estimated for the Monroe Power Plant.

Under equilibrium conditions where $\mathrm{d} B / \mathrm{d} t=0$, the relation between biomass of the standing stock and volume flow is

$B=B_{\propto}(k-q E) / k-\left[(f+h+p) B_{\infty} / k\right] Q$

For every value of the parameters $Q$ and $E$ such that

$k>q E+(f+p+h) Q$

the biomass of the stock will asymptotically approach an equilibrium biomass value greater than zero. The model predicts that neither fishing nor environmental impacts are likely to drive the population to extinction.

Applying the parameter estimates for the Monroe Power Plant the equations relating equilibrium biomass of the standing stock to volume flow for impingement, larval entrainment, and the combined impact of impingement and entrainment are

$$
\begin{aligned}
& B=8325771-8.38 \times 10^{-5} Q \\
& B=8325771-4.69 \times 10^{-6} Q \\
& B=8325771-8.85 \times 10^{-5} Q
\end{aligned}
$$

The equation for the combined impact is plotted in Fig. 3. Biomass of the standing stock decreases linearly as volume flow increases. The impact of impingement appears larger than the impact of entrainment, but assessment of entrainment impact is less certain. The combined impacts of entrainment and impingement reduced the standing stock of yellow perch in the western basin of Lake Erie by about $2 \%$ (Table III).

In assessing the impact of fishing the relation between equilibrium yield and stock size is of major importance. This stock production curve, which is a parabola, gives the sustainable yield for each level of biomass. The MSY occurs at $B_{\infty} / 2$. Under equilibrium conditions the relation between equilibrium yield and biomass for a population subjected to fishing, impingement, and entrainment is given by the equation

$$
Y_{c}=k B-\left(k / B_{\infty}\right) B^{2}-(f+h+p) B Q
$$

The relation between biomass and equilibrium yield is a parabola. Impinge- 


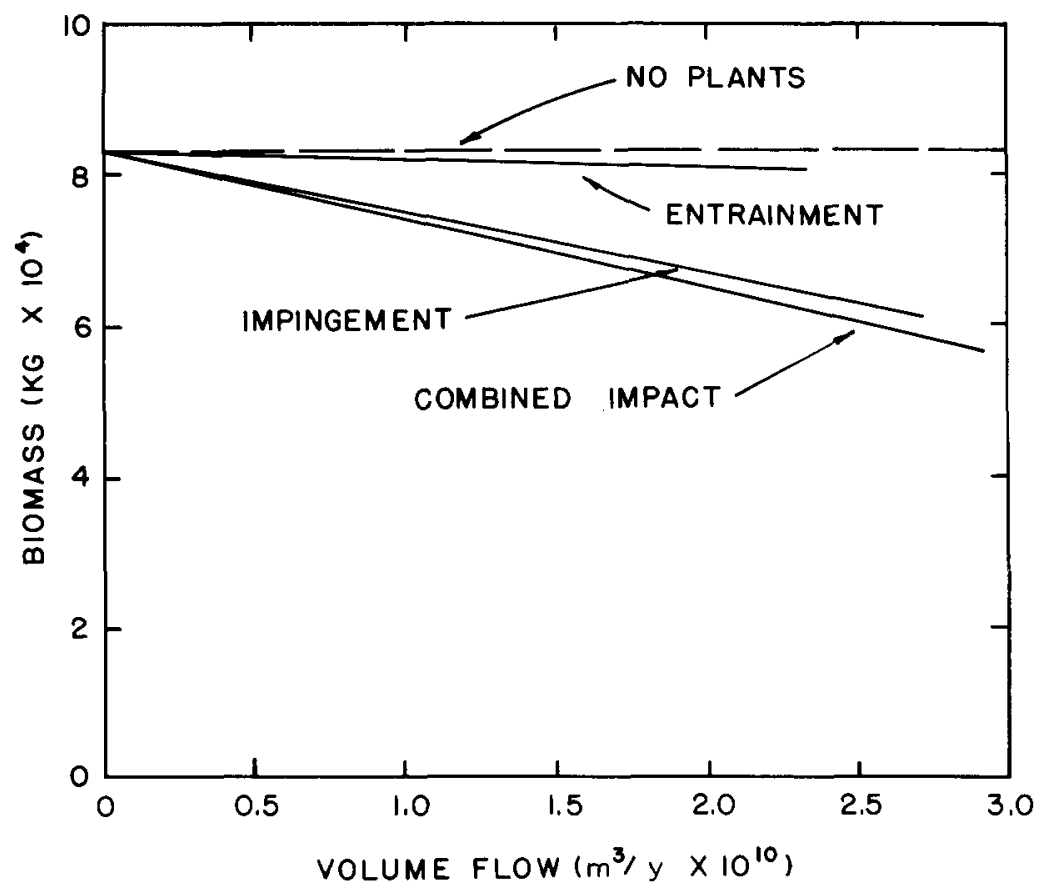

Fig. 3. Equilibrium biomass of yellow perch standing stock as a function of volume of water withdrawal.

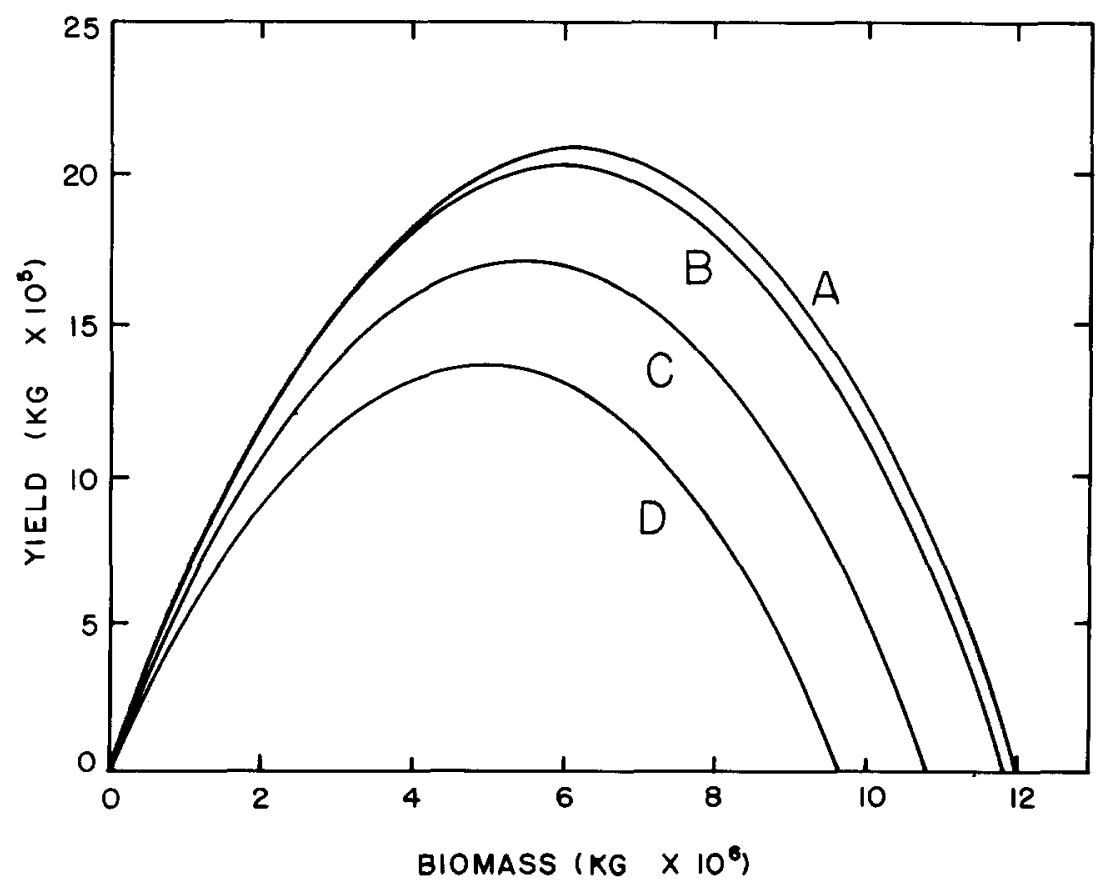

Fig. 4. Equilibrium stock-production curves for yellow perch at different volume flows: $A=0$; $\mathrm{B}=0.3 \times 10^{10} \mathrm{~m}^{3} / \mathrm{y} ; \mathrm{C}=2.0 \times 10^{10} \mathrm{~m}^{3} / \mathrm{y}$; and $\mathrm{D}=4.0 \times 10^{10} \mathrm{~m}^{3} / \mathrm{y}$. 
ment and entrainment cause the entire curve to shift toward the origin (Fig. 4). Both the MSY and the biomass that would exist without fishing are reduced by impingement and entrainment. At the observed flow of $0.186 \times$ $10^{10} \mathrm{~m}^{3} / \mathrm{y}$ the Monroe Power Plant causes only a small change in the stock production curve. An increase in water withdrawal to $2.0 \times 10^{10} \mathrm{~m}^{3} / \mathrm{y}$ would cause a substantial shift in the stock production curve.

Maximum sustainable yield as a function of volume flow can be obtained from eq. 25. The biomass at which the MSY occurs is

$B^{\prime}=(k-f Q-p Q-h Q) B_{\infty} / 2 k$

If volume flow is zero this biomass value becomes $B_{\infty} / 2$ as is necessary. Substitution of $B^{\prime}$ into eq. 25 gives the relation between MSY and volume flow as

$\operatorname{MSY}=\left(k B_{\infty} / 4\right)-\left(f B_{\infty} / 2\right) Q+B_{\infty}(f Q)^{2} / 4 k$

The relation between the MSY and volume flow is quadratic. Substitution of the parameter estimates into eq. 27 gives the following equations for impacts of impingement, entrainment, and the combined impacts of impingement and entrainment on the MSY of yellow perch from the western basin of

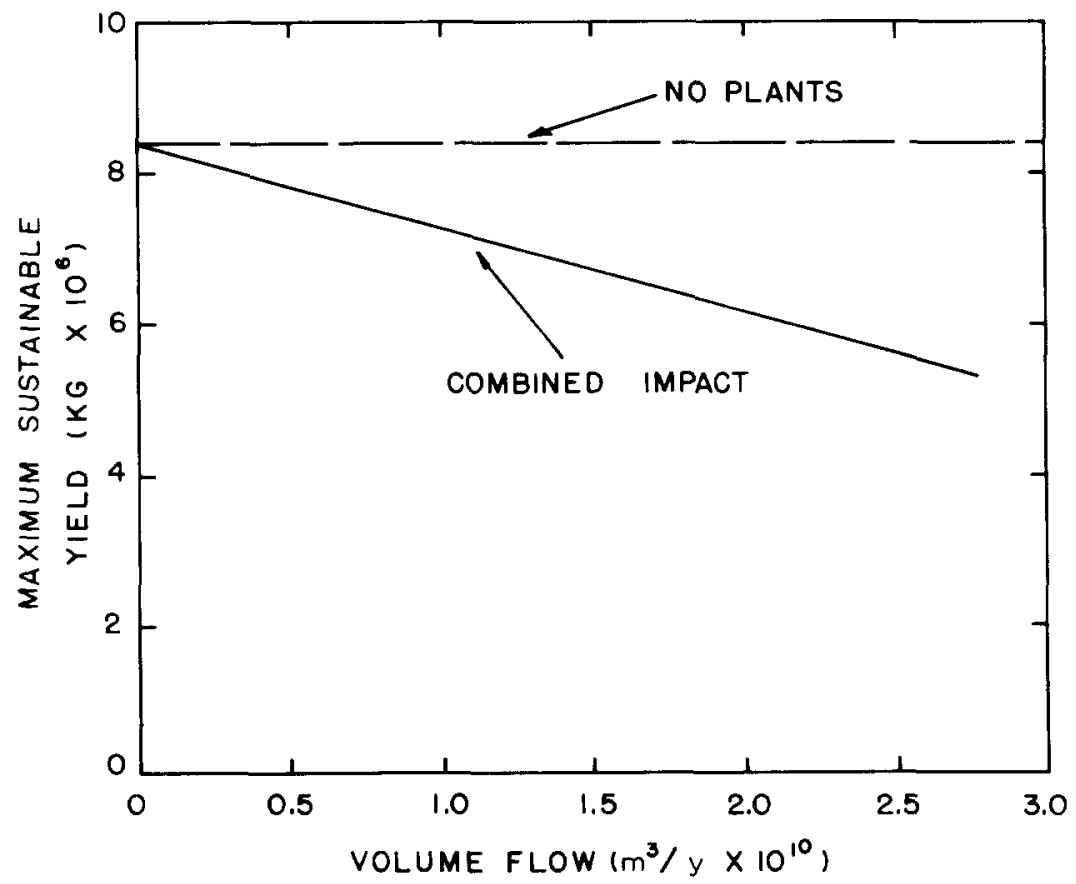

Fig. 5. Maximum sustainable yield of yellow perch as a function of water withdrawal. 
Lake Erie

$$
\begin{aligned}
& \mathrm{MSY}=2100000-2.93 \times 10^{-5} Q+1.02 \times 10^{-16} Q^{2} \\
& \mathrm{MSY}=2100000-1.64 \times 10^{-6} Q+3.21 \times 10^{-15} Q^{2} \\
& \mathrm{MSY}=2100000-3.09 \times 10^{-5} Q+1.14 \times 10^{-16} Q^{2}
\end{aligned}
$$

The relation between the MSY and flow is essentially linear (Fig. 5); the quadratic term is small.

The surplus production model predicts that the impact of entrainment and impingement on the standing stock and MSY are considerably higher than the proportion of the standing stock entrained and impinged (Table III). The impact on the MSY is larger than the impact on the standing stock.

\section{SENSITIVITY ANALYSIS}

Predictions of impact might be in error if either the structure of the model or the parameter estimates are incorrect. Several modififcations of the logistic surplus production model have been proposed; they are similar to modifications of the logistic equation made by earlier workers. Pella and Tomlinson (1969) developed and applied a more flexible relation between yield and population size. Walter (1973) and Marchesseault et al. (1976) introduced time lags, and Marchesseault et al. (1976) showed that with a reproductive time lag the conditions for optimum yield were more conservative than those for the logistic model. Ricker (1958) and Beddington and May (1977) developed stochastic models and both showed that the optimum levels of exploitation were lower with environmental variation. Clark (1973) developed a modification in which extinction occurs if the population size falls below a critical level.

These modifications add flexibility and realistic features to the logistic model and if it were not for the difficulty of parameter estimation and model verification these modifications might be widely applied for stock assessment. In this study it was expected that the power plant impact would be substantially less than that of the fishery and that the above modifications would not substantially alter conclusions. The logistic model was selected because it is the simplest, it provides a practical description of the major features of interest, and it has fewer parameters than other models. The logistic surplus production model was developed in the late 1920s and 1930 s by Volterra (1928), Hjort et al. (1933), and Graham (1935), and it has been widely applied for stock assessment (Jensen, 1976, 1978; Pella and Tomlinson, 1969; Fox, 1970; and Schaefer, 1954, 1957). The model has been verified in laboratory studies of fish subjected to exploitation (Silliman, 1971) and the model is a commonly applied biological model for bioeco- 
nomic analyses of fisheries (Anderson, 1977). The assumptions of the model have been discussed in detail in the above papers; especially by Jensen (1976) and Pella and Tomlinson (1969).

The model is applied for estimation of stock biomass. Considerable changes in the biomass estimates do not result in large changes in the estimate of the proportion impinged (Fig. 6). The same result is true for larval entrainment; large changes in biomass do not produce correspondingly large changes in the proportion entrained.

There are 4 parameters of the model that are of importance in evaluating the level of impact- $\phi_{1}, q, k$, and $B_{\infty}$. The relations of biomass and the maximum sustainable yield to flow are similar so only the impact of changes in the parameters on the relation between biomass and flow will be examined. The relationships between $B$ and $Q$ for 2 different values of $q$ are shown in Fig. 7. The lines are parallel and the biomass entrained and impinged, which is the distance between the solid lines and the corresponding dashed lines, does not change as $q$ changes. As $q$ decreases, however, the estimates of population biomass decrease and the proportion impinged and entrained increases. The change in the proportions is much smaller than the change in $q$.

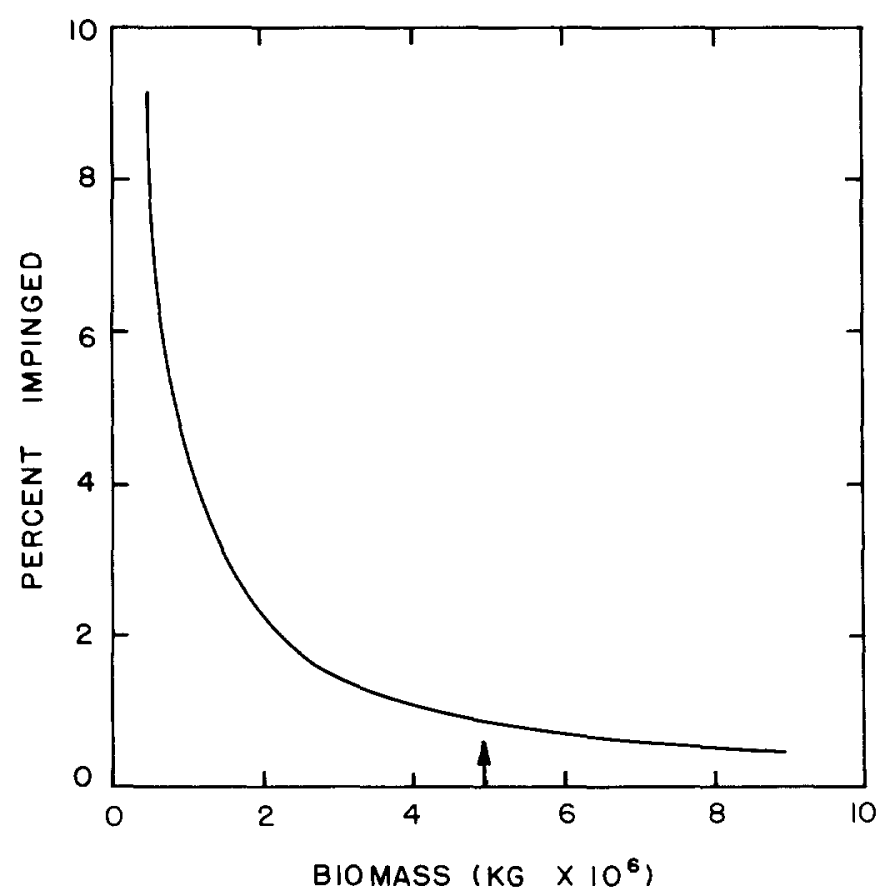

Fig. 6. Relation between biomass of the standing stock and the estimate of proportion impinged. The arrow indicates the observed biomass. 


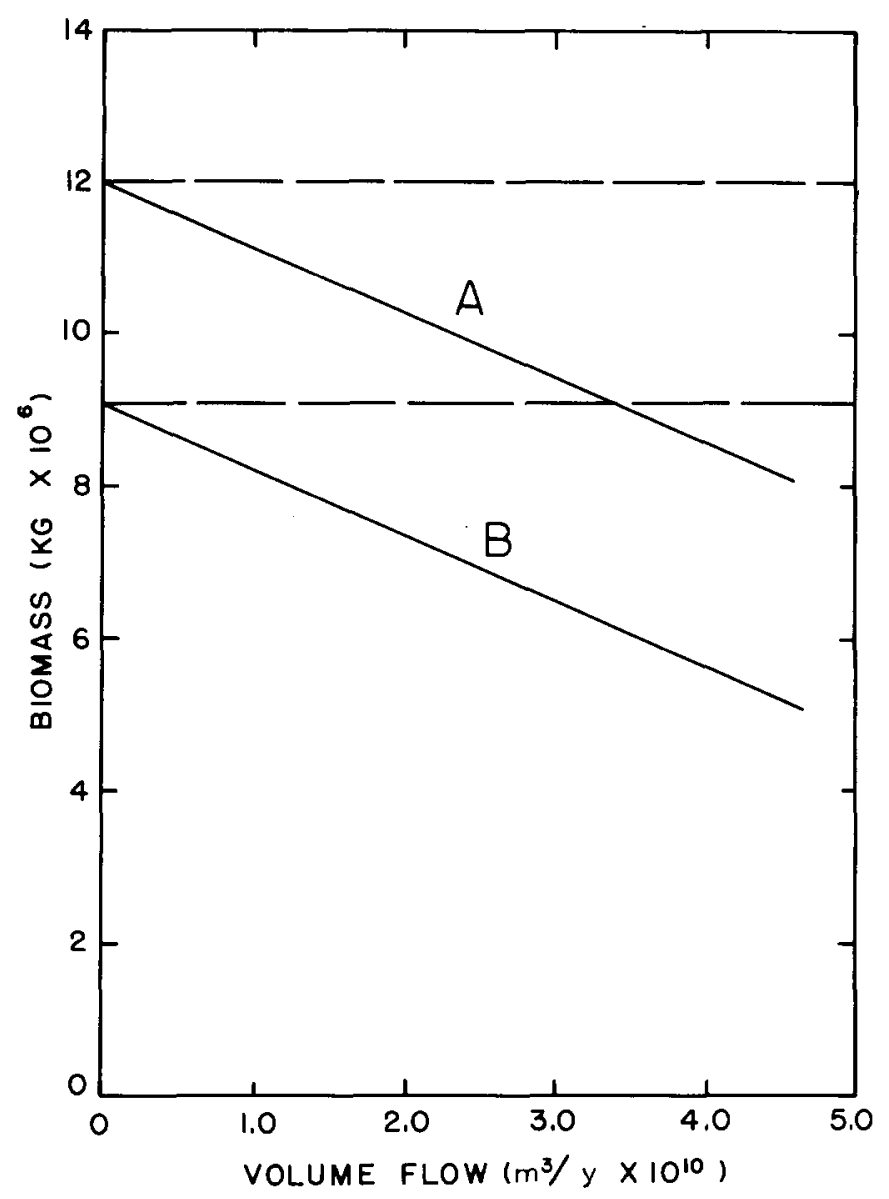

Fig. 7. Relation between equilibrium biomass of the standing stock and volume flow for two values of the catchability coefficient $(A=0.000005$ and $B=0.00005)$.

The relationships between $B$ and $Q$ for 3 different levels of $k$ are shown in Fig. 8. As the value of $k$ decreases the impact increases. The lines are almost parallel and a change in $k$ causes about the same percentage change in impact. The relationships between $B$ and $Q$ for 3 different levels of $B_{\infty}$ are shown in Fig. 9. As the value of $B_{\infty}$ decreases the level of impact increases. The lines converge, but the percentage error in the parameter estimate is about the same as the percentage error in estimation of impact.

A decrease in $q, k$, and $B_{\infty}$ all increase impact. In least squares fitting of the model a higher value of one or more parameters tends to be associated with a lower value of the others and it is unlikely that all parameters will be over-estimated or under-estimated. Errors in $q, k$, and $B_{\infty}$ tend to cancel. Because the impact is small, substantial errors of estimation of the parame- 


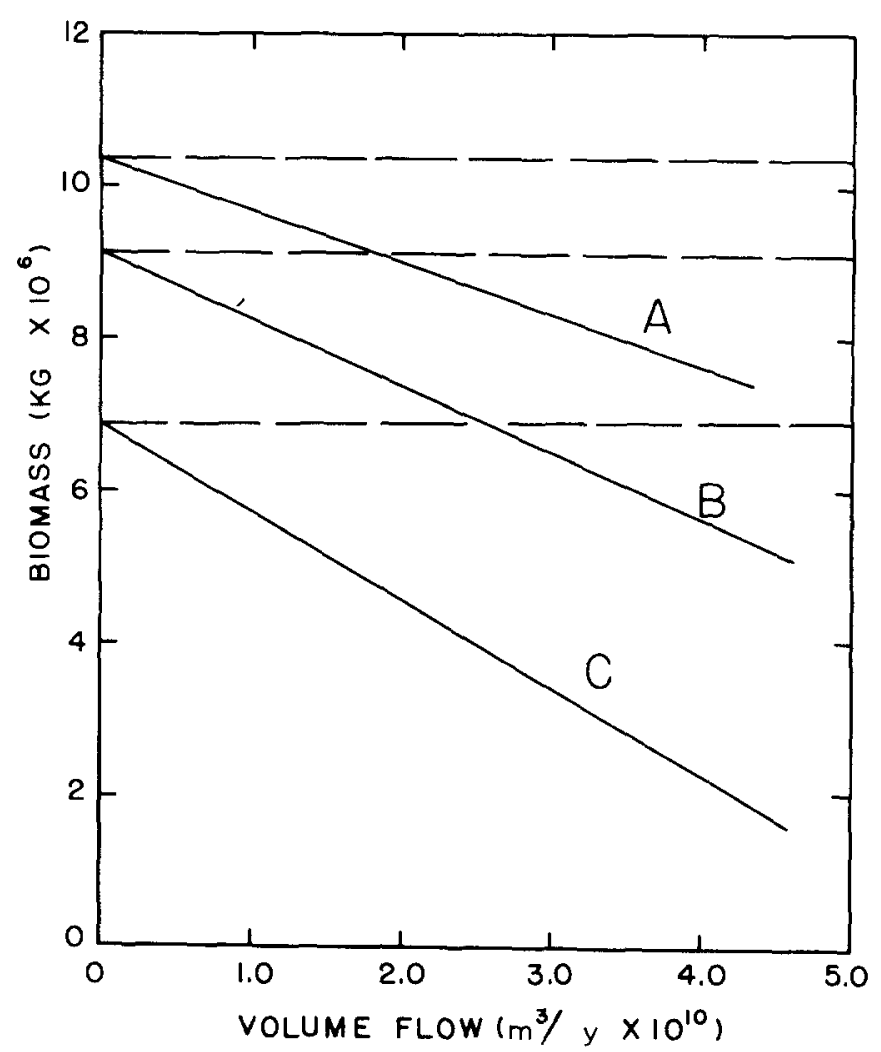

Fig. 8. Relation between biomass of the standing stock and volume of water withdrawal for 3 values of the population growth parameter, $k(\mathrm{~A}=0.70, \mathrm{~B}=0.55$, and $\mathrm{C}=0.40)$.

ters are unlikely to result in an error that is of practical significance.

The egg survival parameter $\phi_{1}$ is the most troublesome parameter as data for estimation of the parameter cannot be easily obtained. Estimates of mortality from the egg to the larva stage vary from $0.50-0.75$ (Patterson, 1979). Within this range of values, large errors in $\phi_{1}$ produce only small changes in impact (Fig. 10). The impact begins to increase rapidly when mortality is increased to about 0.95 . In this study, mortality was set at 0.99 which results in a high impact of entrainment on larvae. Still, the impact of entrainment appears small compared to the impact of impingement.

In summary, the surplus production model, a conventional fishery stock assessment model was applied for assessment of entrainment and impingement impacts. Because impingement is similar to fishing, considerable confidence can be placed in impingement assessments using this model. Entrainment assessment is somewhat uncertain because of the lack of ecological information concerning the early life stages of fish. Most of the parameters 


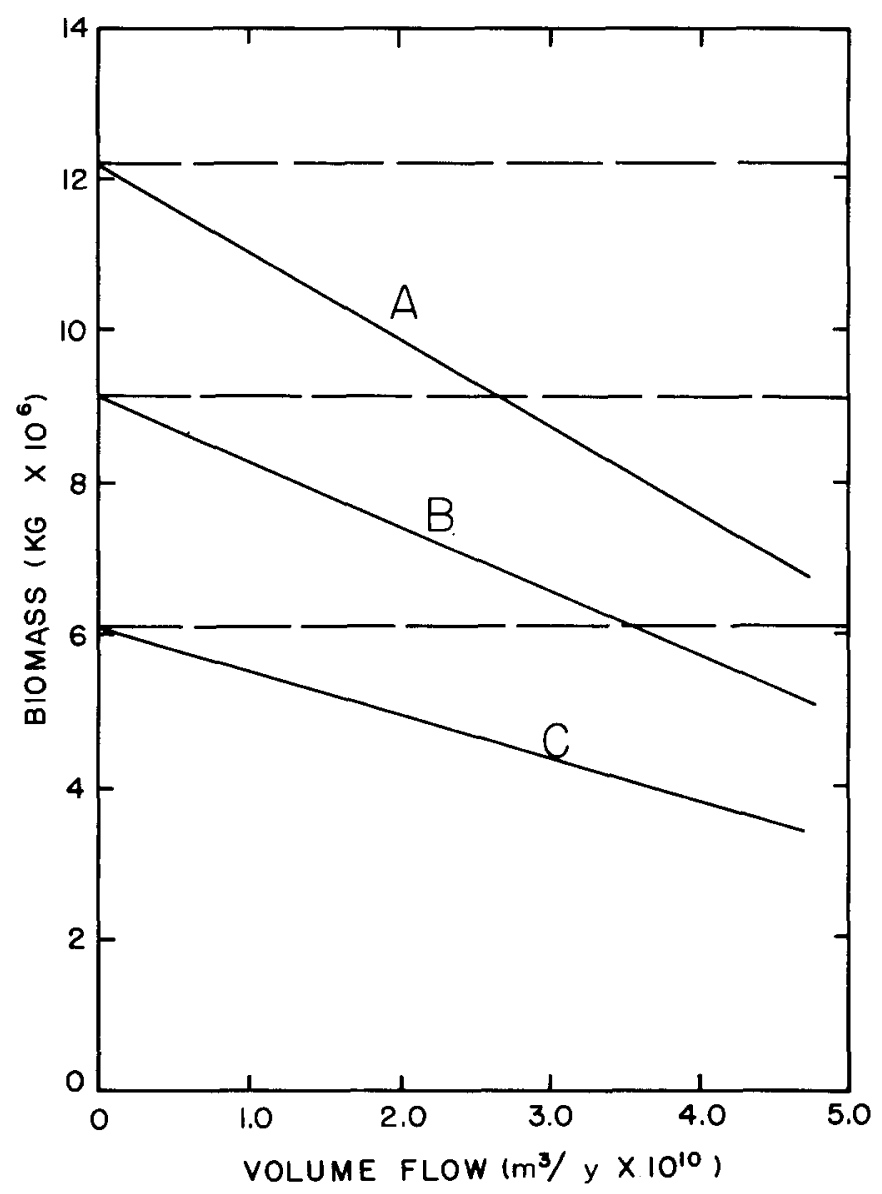

Fig. 9. Relation between biomass of the standing stock and volume flow of withdrawal for 3 values of the carrying capacity, $B_{\infty},(\mathrm{A}=20000000 \mathrm{~kg}, \mathrm{~B}=15000000 \mathrm{~kg}$, and $\mathrm{C}=10000000$ $\mathrm{kg}$ ).

of the surplus production model can be estimated objectively from catch and effort data and power plant entrainment data. The fitted model indicates that the level of impact is larger than is indicated by direct comparison of the numbers entrained and impinged with the standing stock, but the impact is still relatively small. Although the impact of the Monroe Power Plant is relatively small there are a number of power stations operating on the same yellow perch stock in the western basin of Lake Erie and the cumulative impact of these water withdrawals should be evaluated. 


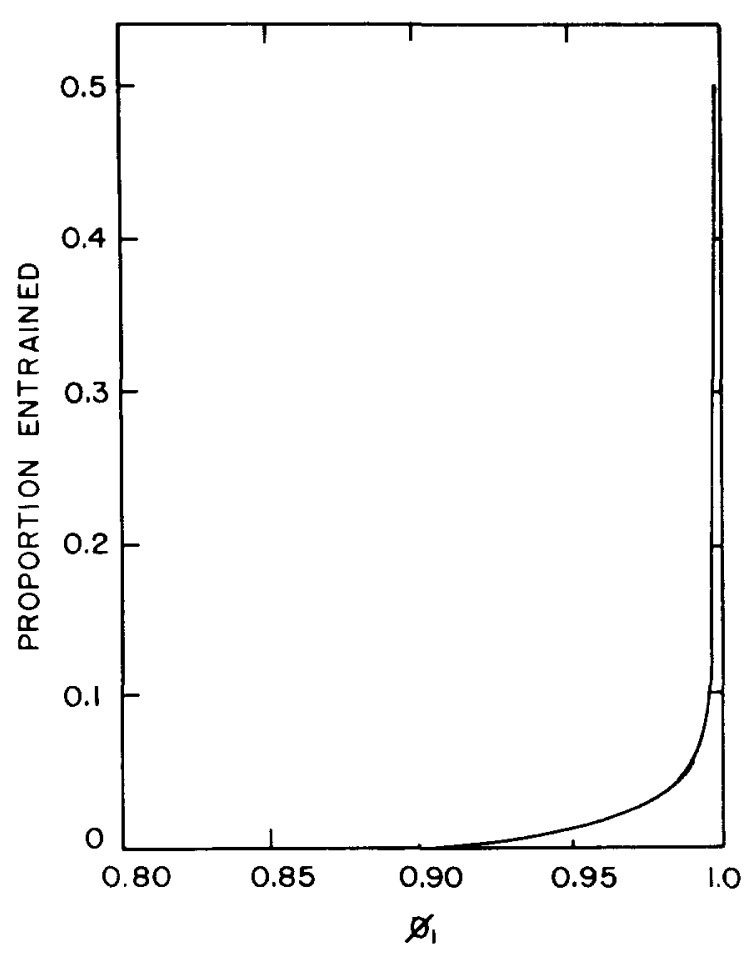

Fig. 10. Relation between the proportion of larvae entrained and the egg mortality coefficient.

\section{REFERENCES}

Anderson, L.G., 1977. The economics of fisheries management. Johns Hopkins University Press, Baltimore, MD, $214 \mathrm{pp}$.

Anon., 1976. Monroe Power Plant study report on cooling water intake. Detroit Edison Co., Detroit, MI.

Beddington, J.R. and May, R.M., 1977. Harvesting natural populations in a randomly fluctuating environment. Science, 197: 463-465.

Clark, C.W., 1973. The economics of overexploitation. Science, 181:630-534.

Cole, R.A., 1978. Entrainment at a once-through cooling system on western Lake Eric. EPA Research Report No. EPA-60013-78-070, 139 pp.

Fox, W.W.. 1970. An exponential surplus-yield model for optimizing exploited fish populations. Trans. Am. Fish. Soc., 99: 80-88.

Graham, M., 1935, Modern theory of exploiting a fishery, and application to North Sea trawling. J. Cons. Cons. Int. Explor. Mer, 10: 264-274.

Hjort, J., Jahn, G. and Ottestad, P., 1933. The optimum catch. Hvalradets Skr., 7: 92-127. Jensen, A.L., 1976. Assessment of the United States lake whitefish fisheries of Lake Superior. Lake Michigan, and Lake Huron. J. Fish. Res. Board Can., 33: 747-759.

Jensen, A.L., 1978. Assessment of the lake trout fishery in Lake Superior: 1929-1950. Trans. Am. Fish. Soc., 107: 543-549. 
Patterson, R.L., 1979. Production, mortality, and power plant entrainment of larval yellow perch in western Lake Erie. EPA Research Report No. EPA-600/3-79-087, 186 pp.

Pella, J.J. and Tomlinson, P.K., 1969. A generalized stock production model. Inter. Am. Trop. Tuna Comm. Bull., 13: 419-496.

Marchesseault, G.D., Saila, S.B. and Palm, W.J., 1976. Delayed recruitment models and their application to the American lobster (Homarus americanus) fishery. J. Fish. Res. Board Can., 33: 1779-1787.

Schaefer, M.B., 1954. Some aspects of the dynamics of populations important to the management of commercial marine fisheries. Inter. Am. Trop. Tuna Comm. Bull., 1: $27-56$.

Schaefer, M.B., 1957. A study of the dynamics of the fishery for yellowfin tuna in the eastern tropical Pacific Ocean. Inter. Am. Trop. Tuna Comm. Bull, 2: 245-268.

Silliman, R.P., 1971. Advantages and limitations of simple fishery models in light of laboratory experiments. J. Fish. Res. Board Can., 28: 1211-1214.

Ricker, W.E., 1958. Maximum sustained yields from fluctuating environments and mixed stocks. J. Fish. Res. Board Can., 15: 991-1006.

Thorpe, J., 1977. Synopsis of biological data on the perch. F.A.O. Fisheries Synopsis No. 113 , $138 \mathrm{pp}$.

Volterra, V., 1928. Variations and fluctuations of the number of individuals in animal species living together. J. Cons. Cons. Int. Explor. Mer, 3: 1-51.

Walter, G.G., 1973. Delay-differential equation models for fisheries. J. Fish. Res. Board Can., 30: 939-945. 